\title{
A INTERNET DAS COISAS - PANÓPTICO ENQUANTO INTRUMENTO DE BIOPODER
}

\author{
Solange Teresinha Carvalho Pissolato ${ }^{1}$ \\ Walkíria Martinez Henrich Ferrer ${ }^{2}$ \\ Bruno Bastos de Oliveira ${ }^{3}$
}

Resumo: O artigo discute a utilização da Internet das Coisas e o panóptico como instrumento de biopoder em espaços de atuação de vigilância e controle populacional. Metodologicamente, trata-se de pesquisa qualitativa, método dedutivo, com aporte na pesquisa teórica e revisão bibliográfica. Conclui-se que a internet das coisas é uma forma de exercício do biopoder e trouxe grande repercussão em princípios constitucionais estruturantes voltados à intimidade, privacidade e sigilo das comunicações, interferindo de forma significativa no comportamento do usuário.

Palavras-chave: Biopoder. Biopolítica. Internet das Coisas. Panóptico. Perigos invisíveis.

\section{THE INTERNET OF THINGS - PANÓPTICO AS BIOPOWER INTRUMENT}

\begin{abstract}
The article discusses the use of the Internet of Things and the panopticon as an instrument of biopower, in areas of population surveillance and control. Methodologically, it is a qualitative research, deductive method, with a contribution to theoretical research and bibliographic review. It is concluded that the internet of things, is a form of exercise of biopower and brought great repercussions on structural constitutional principles aimed at the intimacy, privacy and secrecy of communications, significantly interfering in the user's behavior.
\end{abstract}

Keywords: Biopower. Biopolitics. Internet of Things. Panopticon. Invisible Dangers.

\section{INTRODUÇÃO}

De forma repentina e ressonante, a sociedade sofreu grandes transformações, principalmente a partir das últimas décadas do século XX, ganhando novas adjetivações como sociedade hipermoderna e globalizada, considerando, em especial, o avanço da tecnologia, vivenciada pela ascensão do mundo digital oportunizado pela internet, responsável pela

\footnotetext{
1 Mestranda em Direito pelo Programa de Pós-graduação em Direito da Universidade de Marília (PPGD UNIMAR).

${ }^{2}$ Doutora em Educação e Professora Permanente do Programa de Pós-graduação em Direito da Universidade de Marília (PPGD UNIMAR).
} 
capilarização de variadas formas digitais de comunicação, inserindo a sociedade na era da (des)informação, reestruturando as relações sociais de uma maneira muito profunda.

A rede mundial de computadores fomentou a hiperconectividade ${ }^{4}$ e potencializou a globalização da economia, e é inegável que estamos imersos em um mundo marcado pela presença de aparatos tecnológicos e digitais. Há uma tendência crescente de que todos os objetos existentes no mundo tendam a se conectar à rede de computadores, tornando possível o acesso e a conexão de milhares de pessoas em diversos lugares do mundo, configurando uma comunicação instantânea. Para muito além de um meio pelo qual as notícias ou informações são transmitidas mais rapidamente, sua existência altera a estrutura da natureza íntima e de aspectos pessoais da experiência cotidiana.

Há que se considerar ainda a transferência de dados, informações por e-mail, compartilhamento de fotos, vídeos e músicas em tempo real, via streaming ou plataformas digitais. Tais conexões não se restringem apenas a objetos, mas, na verdade, configuram-se como interações inteligentes, como no caso do uso de tecnologias de segurança mais modernas com dispositivos embarcadas em equipamentos eletro-eletrônicos, oportunizando o monitoramento por câmaras de segurança, senhas eletrônicas e biométricas, leitura de íris e reconhecimento e comando de voz presencial ou remoto, e que passaram a compor e executar as funções mais cotidianas das pessoas, de forma muito sutil e quase imperceptível, deixando pegadas digitais para construção do perfil do usuário.

O mundo passa por um processo vertiginoso de hiperconectividade, e a tecnologia franqueia e capilariza aos equipamentos utilizados na rotina diária uma conexão com a internet quase que de maneira autônoma, vez que se a senha do wifi (dispositivo sem fio para acesso à internet) de um determinado ambiente já foi cadastrada no equipamento anteriormente, basta acessar o local, fisicamente ou não, para que a conexão ocorra de pronto. Previamente, o destinatário final dos produtos das empresas desenvolvedoras da $\operatorname{IoTs}^{5}$ era o

\footnotetext{
3 Doutor em Ciências Jurídicas e Professor Permanente do Programa de Pós-graduação em Direito da Universidade de Marília (PPGD UNIMAR).

${ }^{4} \mathrm{O}$ atual cenário de hiperconectividade é, portanto, baseado na estreita relação entre seres humanos, objetos físicos, sensores, algoritmos, Big Data, Inteligência Artificial (computacional), cloud computing, entre outros elementos [...]. O termo hiperconectividade foi cunhado inicialmente para descrever o estado de disponibilidade dos indivíduos para se comunicar a qualquer momento (MAGRANI, 2019).

${ }^{5}$ Para o consórcio PoETAS.IT (Políticas e Estratégias para Tecnologias, Aplicações e Serviços para a Internet de Tudo), o conceito de IoT consiste em estar "Tudo interconectado: itens do dia a dia, máquinas e objetos em geral, ligados à rede mundial de computadores e operando em coordenação e sintonia". Além disso, o conceito
} 
consumidor comum, atualmente estão ganhando notoriedade uma gama de oportunidades de sua aplicação, como monitores de rastreamento de cargas, a agricultura de precisão e gerenciamento de energias, a infraestrutura voltada a cidades inteligentes, à indústria, saúde, mineração, construção, e também na Administração Pública e governança.

Todos os segmentos da vida humana têm sofrido influência do mundo digital, e a justiça não passou imune às inovações tecnológicas, considerando que há uma grande quantidade de novas ações resultantes da justiça eletrônica, adequando a informatização dos procedimentos no Poder Judiciário, levando a mais Alta Corte do país à expansão dos julgamentos pelo Plenário Virtual em ambiente eletrônico. Desde o advento do processo digital, a automação nos escritórios de advocacia brasileiros é outro desafio do século XXI, adjetivada de advocacia 4.0, por meio da automação das atividades profissionais e uso de softwares jurídicos.

A humanidade tem experienciado mudanças de vários paradigmas, dentre eles a hiperconectivade forjada pela internet e, em especial, pela Internet das Coisas (IoTs). Tal advento, cerne de calorosos debates que não guardam opiniões uníssonas, repercutem na cobrança de respostas jurídicas à crescente demanda que gravita em torno de temas sensíveis do direito contemporâneo, geradores de externalidades positivas e negativas em escala global, as quais vulnerabilizam a dignidade da pessoa humana, mitigando o direito à privacidade, ferindo a sua preservação.

Criamos um mundo em que se tornou fundamental ter conexões virtuais, principalmente para as gerações mais novas, X, Y, Z. Tais conexões vêm impregnadas de uma manipulação sorrateira, e permeia o centro de tudo que fazemos. Não é por outra razão que se conclui que tal realidade transmutou-se de forma hegemônica na contemporaneidade. Nessa linha de pensamento, entende-se ser possível afirmar que, de acordo com a memorável frase de Foucault em seu clássico "Vigiar e Punir", perfeitamente oportuna neste momento, o "preço da liberdade é a eterna vigilância [...]". Da qual se lança a hipótese: toda a liberdade oportunizada pela hiperconetividade da internet das coisas configuraria um panóptico de Biopoder de constante vigilância?

Em contraponto, discutem-se as externalidades positivas e negativas sob o enfoque dos princípios constitucionais. O presente artigo discute a utilização da Internet das Coisas

se relaciona com o chamado "ABC" (Analytics + Big Data + Cloud Computing) das TICs (Tecnologias da 
(IoTs) e o panóptico como forma de biopoder, a partir do viés do novo paradigma da hiperconexão digital que permeia a contemporaneidade em espaços de atuação da vigilância e controle populacional, pautados na arquitetura das relações sociais e de consumo, em que a vigilância cinge a análise sobre o poder, tendo como bibliografia de base o panóptico de Jeremy Bentham pelas lentes de Michel Foucault.

A pesquisa é de cunho qualitativo, e metologicamente se pautou pelo método dedutivo, com aporte na pesquisa bilbiográfica, tendo por escopo discutir a Internet das Coisas (IoTs) como panóptico de biopoder em um capitalismo de vigilância. Sobre essa ótica, a primeira seção apresenta, em linhas gerais, o conceito biopoder e biopolítica sob a concepção de Michel Foucault; na segunda seção, explana-se o tema Internet das Coisas (IoTs), suas principais características e controvérsias na contemporaneidade. Na sequência, discorre-se sobre a sociedade hipermoderna e globalizada, hiperconectividade e os novos desafios, a manipulação e controle dos consumidores/usuários em um capitalismo de vigilância, sob o enfoque dos princípios constitucionais, seguida da conclusão e referências.

\section{BIOPODER E BIOPOLÍTICA: LINHA DO TEMPO E DINÂMICA EVOLUTIVA}

No que tange a temas sensíveis com reflexo, no que pertine ao controle e vigilância de massas, é imperioso trazer à baila conceitos tradicionais que reverberam no tempo e espaço, o que ganha concretrude pelo conceito do "Panóptico", termo cunhado pelo filósofo e jurista inglês Jeremy Bentham, e ulteriormente lapidado por Michel Foucault (FANTECELLE, 2016, p. 140). Preteritamente, a sociedade era estruturada e organizada, fundada em direitos originários e sucessivos, pautados na ancestralidade e consquistas de grupos específicos, em determinado espaço e momento histórico. Constata-se, historicamente, no que pertine ao "termo Panóptico de Bentham", que o controle social se alterou com a chegada da sociedade pós-moderna. A partir da propositura de uma dinâmica evolutiva, utilizando-se da linha do tempo, ocorreu um movimento da era agrária e da era industrial à sociedade da informação (GUNDALINI; TOMIZAWA, 2013).

O termo controle está conexo com o termo panóptico criado por Jeremy Bentham, utilizado de forma peculiar por Michel Foucault para elucidar o papel das instituições sociais 
como hospícios, hospitais, escolas e presídios, forjado como instrumento de disciplina e controle dos doentes, insanos, viciados, leprosos, pestilentos, detentos e estudantes no século XVIII. Com a constante vigilância, submetidos à ação externa, "mentes e corpos humanos poderiam ser moldados por diversas instituições sociais, onde ações de vigilância e adestramento do corpo e da mente, seriam formas de exercer o poder, e produzir um determinado tipo de sociedade" (SANTIAGO; ANDRADE, 2016, p. 1772).

Para além de vigiar, Santiago e Andrade (2016) esclarecem que era preciso construir um sistema de poder capaz de moldar o homem, a fim de torná-lo passivo, útil e disciplinado [...] tal processo Foucault se denomina de poder disciplinar, o qual resulta em uma forma de organizar o espaço físico e utiliza uma técnica que busca segregar, dividir para melhor fiscalizar o individual e controlar o coletivo, resultado de uma necessidade de controle sobre a população, em que a vida torna-se objeto do governo objetivando a manutenção da ordem social.

Foucault, assevera, ao aplicar as técnicas de controle na sociedade, que: "para ser eficiente, o panóptico dever ser 'visível' e 'ínverificável', o indivíduo não precisa saber que está sendo observado, mas precisa ter certeza que poderá sê-lo a qualquer momento" (FOUCAULT, 2001, p. 166).

E, nessa senda argumentativa acerca do controle social, o panóptico de Bentham (1748-1832) simboliza um local onde as pessoas estariam ao entorno dessa estrutura, na qual se poderia ver sem ser visto, configurando-se como instrumento de poder absoluto (SANTIAGO; LACERDA, 2016). A rigor, Foucault não diferencia biopoder e biopolítica; contudo, outros autores passaram a adotar conceitos distintos para os referidos termos, isso repousa em concepções consideradas por Dias e Oliveira (2017, p. 255): “a biopolítica como forma de gerar subjetividade no homem, para compreender a influência estatal e do mercado e posicionar-se perante ela. Biopolítica é a resistência humana em face da tentativa de regulamentação indireta de condutas". Nesse particular, vale registrar que "biopoder seria o exercício dos dispositivos de segurança sobre o homem, com o fim de controlar todos os aspectos de sua vida, e biopolítica seria a resistência do homem em relação a tais dispositivos de segurança, assumnindo o homem o controle de sua vida" (DIAS; OLIVEIRA, 2017, p. 258). Atualmente, as duas formas de poder são pareadas, mas de maneira muito sutil.

Imprescincível analisar que hoje o poder permeia sutilmente todos os lugares e rotinas, materializado na indústria digital, marcada pela hiperconectividade, pelos 
computadores quânticos, internet das coisas (Iots), mídias sociais, plataformas digitais, sistemas educacionais e hospitalares, com especial relevância aos dois últimos exemplos, trazida pela pandemia do Covid 19. Nada escapa às redes sociais: "caiu na rede" dificilmente sairá dela, para Chul-Han (2020, p. 17), “é uma violência viral, aquela da rede e do virtual".

Entoa-se que "há fortes e objetivas razões para se acreditar que estamos atravessando um período de transição histórica, e tais mudanças não estão confinadas a nenhuma área do globo, estendendo-se quase por toda parte", onde a ciência e a tecnologia tornaram-se elas próprias globalizadas (GIDDENS, 2007, p. 13). Tal poder, hoje representado pelo olho cibernético que tudo vê, direcionado à manipulação e controle, é retratado no livro 1984, de George Orwell (2009), que remete a um futuro distópico, no qual tudo é monitorado pelo grande irmão e pelas teletelas, em que todo registro histórico e contemporâneo é controlado pelo ministério da verdade na figura de Winston, que atua como longa manus do Estado, onde as informações disponibilizadas são manipuladas como forma de moldar e mobilizar a opinião pública em prol dos governantes.

Prosperando com a marcação dos algorítimos que, segundo Cathy O`Neil, autora do livro Weapons of Math Destruction, cujo título é trazudido como Algoritmos de destruição em massa, algoritmos ${ }^{6}$ são opiniões embutidas em códigos, cujo princípio norteador é a extração da matéria-prima na forma abundante de dados pessoais com prognósticos relevantes, velozes, precisos e certeiros, que são vendidos aos anunciantes em forma de previsões sobre o comportamento dos usuários.

Tais procedimentos visam antecipar o pensamento e o desejo do consumidor e atender seus anseios, e inevitavelmente a venda de resultados franqueia a possibilidade de modificá-los em larga escala, através da geração de novos anúncios, cuja coleta de novas informações, constitui um conjunto de dados, denominado User Profeile Information, que melhoraria de forma considerável a precisão de tais previsões (ZUBBOF, 2019).

\footnotetext{
${ }^{6}$ O termo "algoritmos" como conjuntos de regras que os computadores seguem para resolver problemas e tomar decisões sobre um determinado curso de ação. Em termos mais técnicos, um algoritmo é uma sequência lógica, finita e definida de instruções que devem ser seguidas para resolver um problema ou executar uma tarefa, ou seja, uma receita que mostra passo a passo os procedimentos necessários para a resolução de uma tarefa (MAGRANI, 2019).
} 
As informações vêm por acumulação e são colhidas pelos excedentes de dados ${ }^{7}$ que fornecem hábitos diários do internauta, suas preferências, que são identificadas por meio dos cliques, da rolagem de tela, da solicitação de documentos, pesquisas ou outros marcadores de comportamento on-line, e através de ferramentas que permitem criar, atualizar ou expandir perfis de usuários. Ações essas que ferem letalmente o princípio da privacidade, pois se apresentam através de uma construção arquitetônica de extração automatizada de dados, com possibilidade de deduzir pensamentos, sentimentos, intenções, rastreando interesses de indivíduos e grupos, desconsiderando a preocupação com a consciência e o consentimento dos envolvidos.

Esse imperativo de extração resultou em economias escaláveis, com a criação de termos próprios a esse novo segmento negocial, estruturado no princípio de subordinação e hierarquia, e, sobretudo para Zubbof (2019, p. 4), concretizadas com uma "vigilância configurada como um espelho unidirecional simbolizado pelas relações sociais de vigilância particulares baseadas em uma espetacular assimetria de conhecimento e poder".

Diante desse contexto, o usuário observado fica imobilizado perante tantas ferramentas de observação, que acabam conhecendo as características, preferências, comportamento, de forma mais assertiva do que o próprio observado, o qual realiza ações de forma inconsciente e passiva, análogo a um avatar manipulado pelas criações das necessidades e demandas impostas pelos anúncios das mídias digitais, implantados em seu subconsciente, seja pelo Facebook, Snapchat, Twitter, Instagram, You Tube, Tik Tok, Google, Pinterest, Reddit, Linkedin, dentre outros. A mudança de comportamento e percepção ocorre de forma gradativa, leve e imperceptível.

Seguindo o raciocínio, terreno fértil para produção de séries televisivas, como Black Mirror, em que um dos episódios apresenta um aplicativo que conecta casais, ancorado em estatísticas e nas similitudes dos parceiros e cujas relações, seu tempo de duração e atividades da vida diária como escolha de cardápios, locais, é determinado pelo dispositivo, tolhendo a liberdade de escolha dos usuários, e quando o usuário não escolhe, vira um alvo fácil (MAGRANI, 2019). No exemplo citado, essa vigilância é exercida através da prescrição de manobras e técnicas, e, conforme nos esclarece Guandalini e Tomizawa (2013, p. 27), o

\footnotetext{
${ }^{7}$ Dados excedentes são informações coletadas para outros fins que não a melhoria dos serviços, constituindo um excedente, e que com base nesse excedente comportamental a empresa alcançaria lucros sustentáveis e exponenciais necessários a sua sobrevivência (ZUBBOF, 2019, p. 3).
} 
poder disciplinar atua de forma sutil, singela e permanente, "alcançando todos os apectos da vida que sejam relevantes para sujeição do indivíduo e a constituição de um corpo útil e dócil, através de um sistema organizado, automático e anônimo".

Para Bauman (2016), liberdade e segurança se apresentam de forma antagônica, são dois valores extremamente difíceis de conciliar. "Para ter mais segurança é preciso renunciar a certa liberdade, se você quer mais liberdade tem que renunciar à segurança”. Giddens (2007, p. 16) defende que a "humanidade pode e deve encontrar meios de tomar as rédeas do mundo em descontrole". E, nesse ponto, destaca-se a posição de Machado, Dias e Ferrer (2018, p. 37), que chamam atenção para a preocupação de que "as redes sociais propiciam as condições adequadas para a chamada transculturação, interação entre os povos, que absorvem diferentes formas de controle e manipulação, o que dá origem à cultura mundial”.

Assim, é pertinente entender que, conforme apontado por Jaron Lanier (2018, p. 13), "todas essas informações e muitas outras têm sido comparadas a leituras semelhantes sobre a vida de milhões por meio de uma espionagem maciça". Não é interessante para o facebook entregar esses dados, ou comercilizá-los, pois são matéria-prima para criação de modelos que preveem as ações dos usuários, e quem tiver o melhor modelo, vence.

Tal eficiência pode ser justificada, visto que, do outro lado da tela, é como se tivessem um boneco de vodu do usuário, um avatar. Tudo que o usuário já fez, todos os cliques, vídeos a que assistiu, as curtidas ou likes, tudo isso ajuda a moldar um modelo cada vez mais fiel dele. Assim que esse modelo é criado, é possível prever "um padrão" de comportamento. Consegue-se prever suas preferências e que tipo de emoções são gatilhos para cada um de forma personalizada (LANIER, 2018).

Significativo é o exemplo: "Pode-se gerar a imagem de um corpo composto apenas por bits contendo informações referentes a diversos corpos. A computação gráfica permite a criação, através de programas computacionais, de uma pessoa virtual, sem refente algum no mundo real" (CHAZAN , 2003).

\section{A INTERNET DAS COISAS (IoTs)}

Postas as premissas do estudo, quais sejam, a definição de biopoder e biopolítica, passa-se, então, à análise do fenômeno IoTs, segundo o viés dos primeiros. Cabe, neste campo introdutório, ao tratar sobre internet das coisas, trazer a conceituação disposta por Deidmar, 
Sobreira e Lima, os quais esclarecem que "em inglês Internet of Things (IOT) o termo consiste na ideia do mundo real com o mundo digital. Os seus objetivos são integrar qualquer dispositivo através da rede de computadores, conectando e automatizando uma série de tarefas do cotidiano melhorando seu dia" (OLIVEIRA; PISSOLATO, 2020).

A IoTs promove uma interação instantânea através dos smartphones, smartwatch, estendendo-se a geladeiras, alarmes, carros, utensílios e eletro-domésticos, com os quais se interage de maneia discreta e quase que involuntariamente, em momentos de digitação, cliques, deslizes de tela ou comando de voz; resulta na mudança de comportamento e do cotidiano das pessoas e pode ganhar uma nova dimensão de inteligência, vez que em muitas situações a participação humana é dispensável como agente ativo nessa interação, configurando-se no que se conhece como M2M, interação máquina a máquina, resultando em maior eficiência no processo (MAGRANI, 2018).

O Brasil está implantando um processo ambicioso, que é Plano Nacional da Internet das Coisas, o qual tem como objetivo que, nos próximos anos, aqui se possa participar cada vez mais dessa onda de objetos conectados, estartado pelo decreto $\mathrm{n}^{\circ}$ 9.854/2019, e, assim, nota-se a preocupação em expandir, aprimorar e aplicar políticas públicas com vistas ao desenvolvimento nacional (BRASIL, 2019).

Quanto ao direito eletrônico no Brasil, verificam-se as agendas governamentais voltadas à positivação da legislação pertinente ao direito eletrônico no Brasil. A Lei Geral de Proteção de dados (LGPD) representou um avanço nesse segmento, somando-se também o decreto 9854/2019, cujo objetivo é a transposição do plano positivado desse estudo de impacto e como isso vai se relacionar na vida cotidiana das pessoas. Visto isso, a tecnologia pode contribuir para a modernização dos sistemas de resolução de disputas e facilitar o acesso à justiça, vez que "o uso da inteligência artificial no sistema judicial já é uma realidade e esse tipo de tecnologia tem se aproximado do cotidiano dos usuários do sistema de justiça, tanto na condição de operadores do direito, e até mesmo dos jurisdicionados"; contudo, ainda apresenta desafios de interconexão entre acesso à justiça e tecnologia (SIQUEIRA; LARA; LIMA, 2020, p. 1.269).

Exsurge assim a discussão sobre as externalidades positivas e negativas marcadas pelas facilidades, vulnerabilidade e riscos a que se expõem quando se trata da própria internet, redes sociais, da internet das coisas (IoTs), a segurança, a privacidade e a dignidade humana, vez que tais objetos geram e coletam novos dados, e os retransmitem, 
retroalimentando a interação das atividades diárias dos seres humanos (OLIVEIRA; PISSOLATO, 2020).

Deve-se levar em consideração a transmutação do comportamento dos cidadãos, vez que "a necessidade de se estar conectado tornou-se tão forte que as pessoas acordam, caminham, alimentam e muitas vezes não dormem, fazendo uso das redes sociais como Facebook, o WhatsApp, entre outros" (SILVA, 2015).

Certo é que o homem contemporâneo é informado sobre a grande quantidade de fatos que dizem respeito à vida coletiva, não havendo preocupação quanto à qualidade da informação, se boa ou má, se verídica ou falsa. Está sempre sobre o influxo da enorme massa de informações que lhe é transmitida a todo instante, há um volume incomensurável de informações, marcado pela velocidade ímpar e pela distância ilimitada, faz-se necessária uma limitação frente à sociedade, seja pelas conversas nos círculos menores, nos locais de trabalho, em meio a grandes multidões, nos veículos de transporte coletivo, em meio a grandes multidões, nos veículos de transporte coletivo, nas casas de diversão, através dos jornais, revistas, livros, aparelhos de rádio, de televisão, filmes etc. (GUNDALINI; TOMIZAWA, 2013).

Do narrado, cabe aplicar a metáfora do panóptico como um olho cuja vigilância, por sua invisibilidade, é constante, cabe a analogia de que as tecnologias que compõem a IoTs se amoldam a esse paradigma.

\section{SOCIEDADE HIPERMODERNA E GLOBALIZADA, HIPERCONECTIVIDADE E OS NOVOS DESAFIOS SOB O ENFOQUE DOS PRINCÍPIOS CONSTITUCIONAIS}

Vivemos em um mundo de transformações, que afetam quase todos os aspectos do que fazemos, "para o bem ou para o mal, e, nessa linha de pensamento, estamos sendo impelidos rumo a uma ordem global que ninguém compreende plenamente, mas cujos efeitos se fazem sentir sobre todos nós" (GIDDENS, p. 17).

Por sua vez, Amartya Sen (2000) pondera que o desenvolvimento pode ser visto como um processo de expansão de liberdades reais que as pessoas desfrutam, ou seja, intimamente ligado à retirada de obstáculos, à expansão da autonomia das pessoas e ao exercício das suas capacidades. Noutras palavras: o desenvolvimento seria fruto de transformações sociais. Nesse contexto, convém trazer à baila, de forma preliminar, o 
entendimento acerca do termo modernidade, tão bem debatido por Giddens (1991), o qual discute o termo considerando algumas variáveis como tempo, espaço, descontinuidade, do que conlcui o autor que, em algum tempo, "Toda espécie humana se torna um museu imaginário onde todos visitam em algum final de semana" (prefácio). Definindo a “modernidade em uma primeira aproximação, como a que se refere a estilo, costume de vida ou organização social que emergiram na Europa a partir do Século XVII, e que ulteriormente se tornaram mais ou menos mundiais em sua influência” (GIDDENS, 1991, p. 11).

$\mathrm{Na}$ mesma linha de pensamento, no parágrafo anterior, segue o autor esclarecendo que isso associa a modernidade a "um período de tempo e a uma localização geográfica inicial". Advertindo que, para além da modernidade, se podem perceber "os contornos de uma ordem nova e diferente, que é pós-moderna, diferindo do que é atualmente chamado por muitos de pós-modernidade", contudo oberva que a história humana é marcada por certas descontinuidades e não tem uma forma homogênea de desenvolvimento (GIDDENS, 1991, p. 12).

Visto pelas lentes de Zygmunt Bauman, que traz a percepção da "modernidade líquida”, em entrevista ao jornal El País (2016), explicou que não há mais um “compromisso sólido" em diferentes esferas, como o Estado, o emprego e a comunidade em que se vive, por exemplo, uma etapa na qual tudo que era sólido se liquidificou, e que "nossos acordos são temporários, passageiros, válidos apenas até novo aviso”. Em percuciente exame da questão, registra-se que, após a Revolução Industrial, a história do pensamento jurídico sofreu mudanças a partir de meados do século XX. Tal período, denominado como pósmodernidade, para Carmo e Messias (2020, p. 210) “caracteriza-se pela socialização e constitucionalização do Direito, assumindo, a principiologia constitucional, antes ocupado pelo positivismo jurídico, representado pelas codificações". Nessa linha de pensamento, a pós-modernidade é caracterizada pela irradiação de normas (princípios e regras, sendo que os princípios passaram a possuir força normativa, representando atuação contra todo o sistema jurídico (CARMO; MESSIAS, 2020, p. 213).

Em que pesem os direito fundamentais envolvendo o direito à privacidade ou sigilo das comunicações, "não podemos perder de vista que tais garantias não podem ser encaradas como absolutas, ou mesmo refúgio para impunidade, e podem ser flexibilizados sempre que o interesse público estiver no outro lado da balança" (FANTECELLE, 2016, p. 152).

Diante dessa questão da garantia ao direito à privacidade, uma indagação que não 
quer calar é se "as pessoas estariam dispostas a renunciar à proteção de seus dados em contrapartida aos benefícios evidentes que tal tecnologia gera em suas vidas, justificando essa troca com base numa conveniência pessoal evidente" (MAGRANI, 2019, p. 16). É certo que o desenvolvimento social e econômico proporcionam à humanidade "uma vida mais próspera, justa e solidária, a redução de desigualdades sociais, a oferta de oportunidades de desenvolvimento e crescimento pessoal, bem como a diminuição da pobreza e da marginalização, dignificando a existência da pessoa humana" (FRAGA; FERREIRA; OLIVEIRA, 2020, p. 7).

Deve-se ter atenção, conforme orientação de Carmo e Almeida (2019, p. 51), que a evolução sócio-econômico-histórica da humanidade, moldada a partir do advento do neoliberalismo, constrói a vida em sociedade através do controle, macro e micro, do comportamento humano, justificando, com o início das novas tecnologias, o comércio da vida em todas as circunstâncias sociais.

É primordial destacar que direito não se aplica em abstrato, ele é produto da realidade social e a ela está atrelado. Porém, passa também pela observância de valores fundamentais balizados constitucionalmente, positivados na Constituição Federal de 1988, que protege de maneira esparsa o direito à privacidade, englobando a proteção aos dados pessoais, tanto no meio físico como digital.

Dentre os direitos fundamentais, a Constituiçao Federal prevê, em seu artigo $5^{\circ}$, a inviolabilidade da intimidade e da vida privada. No ordenamento infraconstitucional, o Código Civil, o Código de Defesa do Consumidor (CDC) e mais recentemente o Marco Civil da internet (MCI), disciplinaram forma mais específica essa proteção (MAGRANI, 2019). A economia, tal como direito, também é parte da realidade social e das transformações históricas. Nesse viés, cabe destacar, na Constituição Federal de 88, a livre iniciativa e a dimensão por ela alcançada no século XX, o constituinte brasileiro tratou-a como princípio constitucional, mais que isso, como fundamento da República Federativa do Brasil, art. $1^{\circ}$ inciso - IV.

Quanto à relevância da livre iniciativa, constata-se, pelo enquadramento dúplice, na Carta Magna foi erigida a condição de fundamento da ordem econômica e simultaneamente princípio constitucional fundamental (art. $1^{\circ}$ IV), sendo citada também no art. 170, que a aponta como basilar na Ordem Econômica, ao lado da valorização do trabalho Humano. A livre-iniciativa tem por fim assegurar a todos existência digna, conforme os ditames da justiça 
social, observados os seguintes princípios: I - soberania nacional; II - propriedade privada; III - função social da propriedade; IV - livre concorrência; V - defesa do consumidor; VI - defesa do meio ambiente, inclusive mediante tratamento diferenciado conforme o impacto ambiental dos produtos e serviços e de seus processos de elaboração e prestação; VII - redução das desigualdades regionais e sociais; VIII - busca do pleno emprego; IX - tratamento favorecido para as empresas de pequeno porte constituídas sob as leis brasileiras e que tenham sua sede e administração no país. O texto Constitucional, de nítido perfil econômico, elencou princípios específicos que, contudo, nem sempre são observados.

A revolução digital coloca em cheque vários princípios, como soberania nacional, visto que pode ferir letalmente a livre concorrência, dentre outros princípios acima elencados. Em contraponto, a própria natureza do capitalismo da informação é um projeto de vigilância altamente lucrativo, que não se submete a barreiras físicas e geográficas, em que a internet gera informações do internauta onde quer que esteja, para publicidade direcionada, com informações dos perfis dos usuários com fins de usá-las para a disseminação de anúncios. No que pertine ao Pleno emprego, o que se constata na prática do Facebook e Googlee, empresas muito bem sucedidas, é que estampam, contudo, um número discreto de funcionários.

Nos últimos dez anos, as gigantes do mundo digital, Google e Facebook, que Jaron Lanier (2018, p. 17) denomina de "impérios de modificações de comportamento", assim com as maiores empresas do mundo do Vale do Silício, operam vendendo seus usuários. Na verdade, os usuários não pagam diretamente pelos produtos que usam, visto que quem paga são os anunciantes, o produto vendido, na verdade, são os usuários, sua atenção, seu tempo de vida dispendido em horas conectados, e o quanto de tempo está disposto a dar. E há que se destacar uma constatação clássica: "se você não está pagando pelo produto, então você é o produto" (MARTINS, 2015); nossa atenção é vendida aos anunciantes.

Para Zuboff (2019), professora Emérita da Harvard Business School, autora do livro "A Era do Capitalismo de Vigilância", obra destaque de "O dilema das redes", uma produção da NetFlix, na qual pesquisadora detalha os perigos do capitalismo de vigilância e de nosso comportamento na internet, como um novo tipo de mercado, que obtém lucro pelo rastreamento infinito de dados do que cada pessoa faz, monitorados por empresas de tecnologia, que têm como modelo de negócio a garantia de que os anunciantes terão o máximo de sucesso.

Em consonância com o parágrafo anterior, a autora esclarece que, para o negócio ser 
bem suscedido, precisa fazer previsões assertivas, e para isso demanda de uma robusta base de dados, e por isso essas empresas vendem "certezas", que é o sonho de qualquer anunciante, ter a garantia de que seu anúncio será exitoso, e como parâmetro poderia ser citado como exemplo a oferta da mudança de $1 \%$ da percepção do mundo em direção ao objetivo desejado pelo cliente, e isso poderia ter uma significância relevantíssima e valer bilhões.

Seguindo na mesma vertente, Chazam (2003, p. 207) esclarece que, "através de um processo bastante complexo, é estabelecido um futuro como uma promessa e um valor nas sociedades de consumo", pois negocia exclusivamente o futuro do ser humano, em larga escala, produzindo trilhões de dólares, e que tornaram as empresas da internet as mais ricas da história da humanidade. Cada ação é cuidadosamente monitorada e registrada. Sabem quando as pessoas estão solitárias ou deprimidas, sua personalidade, se extrovertido ou tímido, quando olham fotos de ex-companheiros, o que é feito nos vários períodos do dia, e suas neuroses. Nessa linha de raciocínio, Chazan (2003, p. 207) afirma que "a idéia de um constante aprimoramento de si, via consumo, evidencia-se de modo insistente, com ancoragem no viés do panóptico, tudo que é feito na internet, está sendo assistido, rastredo e medido". A rede tem mais informações sobre o usuário do que se imaginou na história da humanidade, é algo sem precedentes, conhece mais o usuário do que ele próprio se conhece.

Ao pensar em como alguma dessas empresas funcionam, tudo faz sentido, visto que há serviços na internet que são considerados gratuitos, mas que na verdade não são, pois são pagos pelos anunciantes em troca de exibir seus anúncios. Coadunando com esse pensamento, Lanier (2018, p. 15) aponta que, "agora que estão todos nas redes sociais, recebem estímulos individualizados, continuamente ajustados, sem trégua, é só estar usando o smarthphone. O que antes podia ser chamado de propaganda, deve agora ser entendido como uma modificação de comportamento permanente e em escala gigantesca".

Assim, assiste razão a importância do pregado por Foucault, 2002, p. 28): "quanto maior o número de informações em relação aos indivíduos, maior a possibilidade de controle de comportamento desses indivíduos". Todos esses dados que são entregues e disponibilizados na rede o tempo todo estão sendo usados para alimentar sistemas sem quase nenhuma supervisão humana, e que fazem previsões cada vez melhores sobre quais futuras ações dos usuários e quem eles são, pensando-se na metáfora do panóptico, "como um olho cuja vigilância, por sua invisibilidade, é constante” (CHAZAN, 2003, p. 207).

A matéria-prima essencial é obtida através da vigilância comercial, são dados 
comportamentais de alto valor agredado que estruturam a construção de um mercado dinâmico de publicidade on-line, fazendo com que, de forma fluida e "voluntária", os usuários manifestem suas vontades e sua capacidade de superar quaisquer atritos relativos aos direitos de “decisão" dos usuários.

Para Jaron Lanier (2018), tal comportamento é explicado no Behaviorismo, que traz como um de seus expoentes B. F. Skinner, que estudava maneiras novas, mais metódicas e estéreis de treinar animais e humanos. Ainda que haja defesa da tese de que, para a utilização de qualquer dispositivo ou realização de uma ação ou compra na internet seja apresentado um ícone, por meio do qual o usuário deva concordar com os termos ali apresentados, como condicionante para dar sequência no procedimento.

O poder passou da opressão para a sedução das espécies encantadas que se submetem ao estresse. Enquanto isso, ao ser alienado, o indivíduo sente-se livre quando sente que está em tudo e o tempo todo. Em economia, nos tornamos todos vendedores, enchemos o mundo com coisas com duração cada vez mais curta. O sujeito contemporâneo, exposto como mercadoria nas redes sociais do hedonismo, é uma alegre vítima da vertigem que impõe ao seu currículo a sociedade do desempenho, sistêmica e autorreferencial ao máximo (AMORIN, 2020). Nessa articulação dinâmica, é exigido, de alguma maneira, um consentimento para ser manipulado, "um fato triste é que podemos treinar alguém usando técnicas behavioristas sem que a pessoa nem sequer se dê conta”, vez que o usuário clica no ícone de forma automática, como estímulo e reforço, sem ao menos ler o conteúdo na maioria das vezes apresentado (LANIER, 2018, p. 16).

Byung Chul-Han, um dos maiores críticos do uso da Internet e da sociedade contemporânea, filósofo sul-coreano que mora na Alemanha, relata a alienação e dominação do "inferno do igual", da "sociedade do cansaço" e da exploração que nos submetemos. Para Baudrillard, apud Chul-Han (2020, p. 15, 16), “quem vive do igual, também perece pelo igual [...] o igual não leva a formação de anticorpos. Num sistema dominado pelo igual, não faz sentido fortalecer os mecanismos de defesa".

Na compreensão de Carmo e Almeida (2019, p. 50-53), ancorada em Foucault, o biopoder, "é a base do desenvolvimento do capitalismo e, nessa perspectiva, inseriu corpos disciplinados dos trabalhadores no aparelho de produção, e buscou ajustar o fenômeno da população aos processos econômicos imediatos". Para os autores, "algumas ações próprias da Biopolítica estatal, não estão pautadas em uma previsão legal expressa. Deve-se ter em mente 
o contexto no qual surgem as normas jurídicas, bem como os impactos dessas normas na realidade e no comportamento das pessoas.

\section{BIOPODER BIOPOLÍTICA E A INTERNET DAS COISAS COMO FERRAMENTA DO CAPITALISMO DE VIGILÂNCIA}

$\mathrm{Na}$ contemporaneidade, surge lógica ousada e inédita de uma nova modelagem empresarial e pretensão comercial, um capitalismo de vigilância sotifisticado, uma declaração de expropriação com fins lucrativos que transforma a realidade em uma extensão de espaços vazios prontos para serem explorados em benefício de outros. Dezenas de pessoas estão viciadas em seus dispositivos eletrônicos, criando uma bolha graças à tecnologia. Tais mudanças decorrem de decisões técnicas provenientes de poucos e jovens profissionais da área de tecnologia, e impactam mais de dois bilhões de pessoas no mundo, pois passam a ter pensamentos que não teriam normalmente, porque um designer gráfico do google decidiu que é assim que as notificações aparecerão na tela do seu dispositivo em que você olha quando acorda.

Para Lanier (2018), isso é feito em consonância com os objetivos da empresa: a) aumentar o engajamento ou seu uso e manter o usuário navagando na rede; b) seja para o crescimento, para que o usuário convide amigos e os faça convidar outros amigos para comunidades; c) de publicidade, para garantir que, enquanto tudo acontece, lucrem o máximo possível com anúncios. Esses objetivos são colocados em prática por algoritmos, cujo trabalho é descobrir o que mostrar ao usuário e para manter os números aumentando. Tais "algoritmos correlacionam o que você faz com o que quase todas as outras pessoas têm feito, ainda que os algoritmos não entendam você de fato, existe o poder nos números, sobretudo nos grandes números" (LANIER, 2018, p. 13).

O que está acontecendo agora, pelas lentes de Bauman (2106), é o que podemos chamar de "crise da democracia, é o colapso da confiança". Destaca ainda o filósofo que, nas redes, é tão fácil adicionar e deletar amigos e controlar as pessoas com quem você se relaciona, que as habilidades sociais não são necessárias. Isso faz com que os indivíduos se sintam um pouco melhor, porque a solidão é a grande ameaça nesses tempos individualistas.

Não há que se negar que o avanço digital e tecnológico trouxe mudanças sistêmicas relevantes ao redor do mundo inteiro, graças ao impacto positivo dessas ferramentas. Por 
outro olhar, tais ferramentas começaram a desequilibrar as relações sociais, o importante é "contrabalancear as externalidades negativas do biopoder com medidas conscientes de biopolítica" (DIAS; OLIVEIRA, 2017, p. 255).

Quando negativas, tais externalidade usualmente geram discriminações atentatórias aos direitos humanos, objetivando ampliar a utilidade e docilidade da vida das pessoas em prol do sistema capitalista. Em contraposição, pelas lentes dos autores Dias e Oliveira, a biopolítica "busca despertar no indivíduo a consciência sobre o movimento quase imperceptível que tem sido estimulado a realizar" (2017, p. 267). Evidentemente que em algum momento o Poder Público é convocado a manifestar-se a respeito das controvérsias marcadas por atividades complexas que repercutem na economia nacional, compondo valores expressivos e objetos adversos como as tecnologias digitais.

Tais ações estão direcionadas na aplicação de alguns dispositivos de segurança aptos ao controle populacional, “A monitoração eletrônica de locais públicos como ruas, praças e parques, ou mesmo de locais particulares de acesso público, como lojas e shopping centers, também são um exemplo de controle do poder público" (FANTECELLE, 2016, p. 153). Assim como pode ser perigosa a excessiva atuação estatal nos domínios da sociedade digital, para Fantecelle (2016, p. 153), sua abstenção é hoje simplesmente impensável, ainda que demande aperfeiçoamento.

Não que haja um posicionamento contrário às iniciativas de intervenção estatal, o que se questiona é se, "em tempos hodiernos, essa vigilância estatal e controle social, justificaria a perda da privacidade das pessoas" (GUANDALINI; TOMIZAWA, 2013, p. 31).

\section{CONCLUSÃO}

O presente artigo discute as reverberações trazidas pela hiperconectividade e as IoTs que inundaram o cotidiano da sociedade contemporânea, configurando-se como um verdadeiro arsenal e instrumento de biopoder, modificando o comportamento e as relações sociais na sociedade globalizada. Utilizou-se, como fio condutor, a perspectiva teórica de Michel Foucault, ancorada no panóptico, biopoder e biopolítica, para conduzir a reflexões e estruturar o olhar sobre a construção arquitetônica da rede, da IoTs e a hiperconectividade fornecida pela internet como instrumento de controle. 
Não que a postura defendida seja o retrocesso tecnológico e a aversão às tecnologias, tampouco a estagnação da economia de mercado, levando em consideração ações tidas como positivas. A intenção aqui postulada foi levar à reflexão crítica, pontuando algumas externalidades, articulando-se esses aspectos de forma a tornar possível sua compreensão e se pensar em soluções efetivas, feito que o direito posto não alcança com a mesma velocidade, a evolução tecnológica como se apresenta.

É certo que tal situação demanda uma forma mais prudente de visualizar possíveis soluções para as externalidades negativas causadas pela hiperconectividade, a partir de possíveis mudanças e ações que para além de melhorar, otimizem e promovam resultados mais efetivos por meio de políticas públicas de prevenção e modulação de tais efeitos.

Por essa análise, o que fica claro é que nós perdemos o poder decisório sobre o que queremos e decidimos, temos a doce ilusão de que exercemos a liberdade, quando na verdade concordamos de forma passiva e sem resistência com aquilo que já foi previamente escolhido para nós. Constata-se que o homem sofreu uma lobotomia social ${ }^{8}$, e foi retirado de sua existência o domínio e o poder sobre si mesmo.

Considerando a discussão sobre biopoder e biopolítica como questões que permeiam as relações sociais, não há como desconsiderar a essencialidade da hiperconectividade no contexto atual, além dos avanços tecnológicos e a evolução digital.

Se por um lado trouxe mudanças sistêmicas relevantes ao redor do mundo inteiro, graças ao impacto positivo dessas ferramentas; por outro olhar, tais ferramentas começaram a desequilibrar as relações sociais. Longe da ingenuidade, em relação ao outro ladro da moeda, é difícil nomear um único problema, visto que são vários, com destaque para fake news, o furto de dados, o vício em aplicativos, polarização de opiniões e influência nas eleições.

Ainda sobre o tema, constata-se que é um caminho sem retorno. Para alguns, saímos da era da informação para a desinformação, de modo que não pudemos evitar abordá-las, mesmo que apenas de passagem, como uma tentativa de expor parte do complexo pano de fundo no qual estão inseridas as questões abordadas neste artigo, por meio da busca de alternativas que amenizem os problemas, ainda que não necessariamente os resolvam.

\footnotetext{
${ }^{8}$ Intervenção cirúrgica no cérebro na qual são seccionadas as vias que ligam as regiões pré-frontais e o tálamo, us. no passado em casos graves de esquizofrenia; leucotomia (A técnica, criada em 1933 pelo médico português A. Egas Moniz 1874-1955, que recebeu por isto o Prêmio Nobel em 1949, encontra-se atualmente em desuso). Em muitos casos, a lobotomia ou transformava os pacientes em vegetais ou simplesmente os tornava mais dóceis, passivos e fáceis de controlar - muitas vezes, menos inteligentes também.
} 
É certo que ocorreu um impulsionamento da produção legislativa no Brasil, e as reflexões acerca das estratégias de facilitação, alinhadas à necessidade de melhoria dos métodos de enfrentamento e prevenção de um colapso social, em que a transformação digital resulta em uma metástase que corrói o tecido social, se não contida.

Como consideraçãoes finais, infere-se que se faz necessária a construção de estratégias que sejam eficazes para o enfrentamento da utilização da IoTs e da inteligência artificial, capazes de integrar tecnologia e segurança, fonte de relevantes preocupações na atualidade.

Por fim, examinando a hiperconexão digital pelo viés dos conceitos de Foucault, constatou-se que os perigos invisíveis tornaram-se evidentes. Do que se conclui que a internet das coisas é uma forma de exercício do biopoder e trouxe grandes repercussões em princípios constitucionais estruturantes voltados à intimidade, privacidade e sigilo das comunicações, interferindo de forma significativa no comportamento do usuário.

\section{REFERÊNCIAS}

BAUMAN, Zygmunt. As redes sociais são uma armadilha. Entrevista concedida ao El pais. Por Ricardo de Querik. 08/01/2016. Disponível em: https://brasil.elpais.com/brasil/2015/12/30/cultura/1451504427_675885.html. Acesso em: 15 jan. 2021.

BRASIL. Constituição da República Federativa do Brasil de 1988. Disponível em: http://www.planalto.gov.br/ccivil_03/constituicao/constituicao.htm. Acesso em: 10 dez. 2020.

BRASIL. Decreto $n^{o}$ 9.854, de 25 de junho de 2019. Disponível em: http://www.planalto.gov.br/ccivil_03/_Ato2019-2022/2019/Decreto/D9854.htm. Acesso em: 20 dez. 2020.

BRASIL. Conselho Nacional de Justiça. Relatório Justiça em números 2019 - ano base 2018. Disponível em: https://www.cnj.jus.br/pesquisas-judiciarias/justica-em-numeros/. Acesso em: 15 ago. 2020.

CARMO, Valter Moura do; ALMEIDA, Patrícia Silva de. Biopoder, Biopolítica e Bioética: Reflexões sobre o aborto seletivo como movimento de Eugenia Pós-Moderna. Revista Brasileira de Direito Animal. Salvador, volume 14, nº 03, p. 42-59, Set.-Dez. 2019. Disponível em: https://portalseer.ufba.br > RBDA. Acesso em: 15 jan. 2021.

CHAZAN, Lilian Krakoswski. O corpo Transparente e o Panóptico Expandido: Considerações sobre as Tecnologias de Imagem nas Reconfigurações da Pessoa Contemporânea. PHYSYS: Ver. Saúde Coletiva, Rio de Janeiro, 13 (1): 193-214, 2003. Disponível em: https://www.scielo.br/pdf/physis/v13n1/a09v13n1.pdf. Acesso em: 10 jan. 
2021.

DIAS, Jefferson Aparecido; OLIVEIRA, Emerson Ademir Borges de. O desemprego e o autoatendimento no setor bancário: entre o Biopoder e a Biopolítica. REPATS, Brasília, V. 4, $\mathrm{n}^{\mathrm{o}} 2, \quad$ p. 253-270, jul.-dez., 2017. Disponível em: https://www12.senado.leg.br/ril/edicoes/55/220/ril_v55_n220_p29. Acesso em: 15 jan. 2021.

FANTECELLE, Gylliard Matos. Modelo Social e o Controle Social na Sociedade Midiatizada. Àguia - Revista Científica da FENORD, julho/2016. Disponível em: http://site.fenord.edu.br/revistaaguia/revista2016/textos/artigo07.pdf. Acesso em: 19 jan. 2021.

FOUCAULT, Michel. Vigiar e Punir. Tradução de Raquel Ramalhete. 28. ed. Petrópolis: Vozes, 2002.

FRAGA, Felipe Vila Boas; FERREIRA, Rui Miguel Zeferino; OLIVEIRA, Bruno Bastos de. O consumo colaborativo como meio de promoção de desenvolvimento nacional sustentável na sociedade hipermoderna. Revista Brasileira de Direito, Passo Fundo, vol. 16, n. 1 p. 1-20, Jan.-Abr., 2020.

GARCIA, Marcelo Guerra. Poder Judiciário em números e o impasse das execuções fiscais no Brasil. Revista Eletrônica de Direito Processual - REDP. Rio de Janeiro. Ano 14. v. 21 n. 1. Jan.-abr. 2020. Disponível em: https://www.epublicacoes.uerj.br/index.php/redp/article/view/43297. Acesso em: 03 set. 2020.

GIDDENS, Anthony. As consequências da modernidade. Tradução de Raul Fiker. São Paulo. Editora Unesp, 1991.

GIDDENS, Anthony. Mundo em descontrole. Tradução de Maria Luiza X. de A. Borges. 6. ed. Rio de Janeiro: Record, 2007.

GUNDALINE, Bruno; TOMIZAWA, Guilherme. Mecanismo Disciplinar de Foucault e o Panótipo de Nentrham na Era da Informação. ANIMA: Revista Eletrônica do Curso de Direito da Faculdades OPET. Curitiba, PR-Brasil, Ano IV, n. 9, jan.-jun. 2013. Disponível em: https://www.google.com/search?nfpr=1\&sxsrf=ALeKk01u4xr1c8BTDvyb0YTU4IUwDwap Og:1612033347326\&q=GUNDALINE,+TOMIZAWA,+Guilherme.+Mecanismo+Disciplinar . Acesso em: 15 jan. 2021.

HAN, Byung-Chul. Sociedade do Cansaço. Tradução de Enio Paulo Giachini. 2. ed. ampliada. 6ª reimpressão. Petrópolis, RJ: Vozes, 2020.

LANNIER, Jaron. Dez argumentos para você deletar agora suas redes sociais. Tradução de Bruno Casotti. Rio de Janeiro: Intrínseca, 2018.

MACHADO, Vinicius Pinheiro; DIAS, Jefferson Aparecido; FERRER, Walkiria Martinez Heinrich. Biopolítica e novas tecnologias. O discurso do ódio na Internet como mecanismo de controle social. RIL, Brasília, a. 55, n. 220, out./dez. 2018, p. 29-51. Disponível em: https://www12.senado.leg.br/ril/edicoes/55/220/ril_v55_n220_p29. Acesso em: 20 dez. 2020. 
MARTINS, Fernando. Quando você é o produto e nem se dá conta disso. Gazeta do Povo. 05/08/2015. Disponível em: https://www.gazetadopovo.com.br/vida-ecidadania/colunistas/fernando-martins/quando-voce-e-o-produto-e-nem-se-da-conta-disso6vsfs4cze1kk851xan1klmj84/. Acesso em: 23 dez. 2020.

MAGRANI, Eduardo. A Internet das Coisas no Brasil. Rio de Janeiro: FGV Editora, 2018.

MENDES, Luciano; BONILHA, Maria Coelho; ICHIKAWA, Elisa Yoshie; SACHUK, Maria Iolanda. Tecnologias Sociais, Biopolíticas e Biopoder: Reflexões Críticas. Cad. EBAPE.BR, v. 13, n. 4, Artigo 2, Rio de Janeiro, out./dez. 2015. Disponível em: http://bibliotecadigital.fgv.br/ojs/index.php/cadernosebape/article/view/13554/55518. Acesso em: 15 jan. 2021.

MESSIAS, Ewerton Ricardo; CARMO, Valter Moura do. Súmula 611 do Superior Tribunal de Justiça: Ativismo Judicial e o Risco à Inviolabilidade da Intimidade, da Vida Privada, da Honra e da Imagem das Pessoas. Revista Direitos Fundamentais e Democracia, v. 25, n. 3. 2020. Disponível em: https://revistaeletronicardfd.unibrasil.com.br/index.php/rdfd/article/view/1616. Acesso em: 19 jan. 2021.

OLIVERA, Bruno Bastos de; PISSOLATO, Solange Teresinha Carvalho. Direito e Tecnologia no Ambiente de Hiperconectividade: Aspectos Jurídicos da Internet das Coisas e seus desafios. Relações Internacionais no Mundo Atual. Revista Unicuritiba, v.1, p. 233-241, 2020.

Disponível

em: http://revista.unicuritiba.edu.br/index.php/RIMA/article/view/4076/371372384. Acesso em: 20 jan. 2021.

ORWELL, George. 1984. Tradução de Alexandre Hubner e Heloisa Jahn. São Paulo: Companhia das Letras, 2009.

SANTIAGO, Mariana Ribeiro; ANDRADE, Sinara Lacerda. A obsolescência programada e psicológica como forma de biopoder: perspectivas do consumo. Quaestio Iuris. Vo. 09, n. 04, Rio de Janeiro, 2016. p. 1771-1786. Disponível em: https://www.epublicacoes.uerj.br/index.php/quaestioiuris/article/view/21252. Acesso em: 10 dez. 2020.

SANTIAGO, Mariana Ribeiro (Org.). Diálogos sobre desenvolvimento, empresa, sociedade (DDES). Evento on-line sobre Sociedade de Desempenho. Palestrante Marcelo Amorin. 29/04/2020. Disponível em: https://www.youtube.com/watch?v=y54euTvJHyM. Acesso em: 03 jul. 2020.

SEN, Amartya. Desenvolvimento como liberdade. Tradução de Laura Teixeira Motta. São Paulo: Companhia das Letras, 2000.

SIQUEIRA, Dirceu Pereira; LARA, Fernando Corrêa; LIMA, Henriqueta Fernanda C. A. F. Acesso à Justiça e Inteligência Artificial: Abordagem a partir da Revisão Sistemática da Literatura. Revista Arugumentum, v. 21, n. 3, p. 1265-1277, Set.-Dez. 2020. Disponível em: http://webcache.googleusercontent.com/search?q=cache:we8YP19bRHwJ:ojs.unimar.br/index 
.php/revistaargumentum/article/download/1386/826+\&cd=1\&hl=pt-BR\&ct=clnk\&gl=br. Acesso em: 15 jan. 2021.

SILVA, Maria do Rosário Martins da. As redes sociais e seus impactos nas relações pessoais. Administradores. 19/122015. Disponível em: https://administradores.com.br/artigos/as-redessociais-e-seus-impactos-nas-relacoes-pessoais. Acesso em: 10 jan. 2021.

ZUBBOF, Shoshana. Tua Escova de dentes te Espiona. Um capitalismo de vigilância. Edição 138, Mundo. Le monde diplomatique Brasil. 03/01/2019. Disponível em: https://diplomatique.org.br/um-capitalismo-de-vigilancia/. Acesso em: 10 jan. 2021. 